\title{
Information and Commentary
}

\section{Clinical epidemiology in developing countries: Current situation and suggestions for the Indian context}

\author{
Rajamohanan K. Pillai * \\ Professor \& HOD Paediatrics, Dr. S.M. C.S.I. Medical College, Karakonam, Kerala, India
}

\section{A R T I C L E I N F O}

\section{Article history:}

Received 4 July 2016

Accepted 22 August 2016

Available online 5 September 2016

\section{Keywords:}

Clinical epidemiology

Evidence based medicine

Clinical epidemiology units

INCLEN

India-CLEN

\begin{abstract}
A B S T R A C T
Background: In India, epidemiological services are well developed and epidemiology teaching is very much part of curriculum from undergraduate to doctorate level of studies. In spite of all the initiatives to sensitize physicians towards clinical epidemiology (CE), this academic discipline is still not popular as it should be. The development of CE teaching and the present situation along with way forward are discussed in this article.

Objectives: This review article is aimed to describe the evolution of CE in India and critically look into the concept and scope of CE and evidence-based medicine (EBM) in the Indian setting.

Methods: This paper is a review of the status of 'clinical epidemiology - popularization' in India and the scope for further progress towards this direction.

Results: The development of CE has taken a new pace after the introduction of EBM. Both CE and EBM are propagated by INCLEN-trained faculty mostly among medical students and teachers. The paper also looks into the linkages between public health epidemiology and CE in the context of involvement of clinical epidemiologists in public health programs.

Conclusions: After discussing the directions for future, the paper proposes the inception of $\mathrm{CE}$ unit at each medical college and also the objectives and structure of such a unit. The article concludes emphasizing the need of public health orientation of CE, the importance of promotion of epidemiology in developing countries through capacity building, and allocation of dedicated funds towards popularization of CE. There is also an urgent need for replication and scale-up of clinical epidemiology unit (CEU) model to other medical colleges.
\end{abstract}

(C) 2016 INDIACLEN. Published by Elsevier, a division of RELX India, Pvt. Ltd. All rights reserved.

* Tel.: +91 9447241692.

E-mail address: drrajamohanank@gmail.com

http://dx.doi.org/10.1016/j.cegh.2016.08.007

2213-3984/C 2016 INDIACLEN. Published by Elsevier, a division of RELX India, Pvt. Ltd. All rights reserved. 


\section{Introduction}

Clinical epidemiology (CE) has now gained a well-established footing in academic institutions, especially in the developed countries. After this strong footing, the discipline is still in the growing phase and needs lot of academic and infrastructure support in the form of capacity building for further popularization. This article is aimed to describe the evolution of CE in India and critically look into the concept and scope of $\mathrm{CE}$ and evidence-based medicine (EBM) in the Indian setting. A discussion on the development of teaching and training part of CE services in India, current status, and the way forward are the objectives of this paper. The paper is primarily targeted to physicians and administrators who are in key positions to provide clinical and public health services and thus influence health policy in the country.

\subsection{Epidemiology in medicine or $C E$}

In the context of the established network of 'epidemiology teaching learning centers', CE is slowly becoming popular in the schools of medicine in India also. ${ }^{1,2}$ Originally, epidemiology was evolved as a fundamental science of public health. When the importance of application of principles of epidemiology in the bedside setting for improving clinical outcomes was recognized, the branch of CE was slowly accepted. During the course of evolution of organized health care, the dichotomy of public health and clinical medicine was inevitable and discussions on this dichotomy still continue. This schism, as it was coined by White, can be considered as one of the causes of low popularity of CE among clinicians. ${ }^{3}$ Clinical practitioners are always concerned with the immediate benefits for their patients and may not use epidemiological principles in their daily practice unless it is convincingly useful for immediate patient benefits. With the evolution of the branch of CE, having tools like diagnostic test evaluation, prognostic prediction, clinical trials, and meta-analysis, CE is becoming more and more popular among clinicians. This may be the main reason for popularity of epidemiology among clinicians rather than a mere attitude of altruism towards scientific practice of medicine. The altruistic concept of practice of medicine as it was discussed needs a deeper understanding of public health. ${ }^{4}$ The criticisms about use of epidemiology by clinicians were discussed in detail by Whelton. ${ }^{5}$

\section{Public health and CE}

After discussing on the popularity of epidemiology in clinical medicine, let us discuss on the applications of epidemiology in public health. In the public health context, application of epidemiological principles is more for prevention than for treatment. In India, integrating prevention to routine functioning of health services was mostly through implementation of public health programs undertaken as a Governmental responsibility. ${ }^{6}$ Public health programs in India are supported by epidemiological database and monitoring and the periodic evaluation is also done based on epidemiological principles. During the implementation of at least some of these programs, private sector which has the vast majority of practicing clinicians in the country, was not taken into full confidence. Of late, this strategy in India was changed and the tuberculosis control program is a typical example of effective public-private partnership. ${ }^{7}$ This private-public dichotomy is perhaps more crucial than the so-called 'public health - clinical schism' in practice and popularization of CE in India.

\section{INCLEN and CE in India}

Popularization of CE formally started in the developing countries with the origin of International Clinical Epidemiology Network in 1980s. ${ }^{8}$ This new network was evolved around academic institutions in order to enlighten clinicians on the need to understand and look critically at available interventions and to popularize rational approach to treatment which is effective, efficient, and acceptable to the patients. The overall purpose was to develop patient-oriented researchers and clinician-investigators who can undertake research with good quality. The INCLEN-trained fellows after coming back to India started an identical network called IndiaCLEN (Indian Clinical Epidemiology Network). Though trained to excel as clinicians and propagate CE, many of the INCLENtrained fellows later on took interest in public health research which also led to better partnerships among academic community medicine departments, program managers, and other researchers. The so-called schism between public health epidemiology and CE was thus converged in a more harmonious manner in India. Clinical orientation of medical research is emphasized by researchers and this is relevant to India also. ${ }^{9}$ A sizable part of clinical research is supported by the drug industry which has limitations in getting the clinicians in public sector to collaborate with them. The Governmental machinery was also demanding the services from this new group of academic experts, specialized in CE and they positively responded to this demand which turned to be fruitful. In addition to their commitment to the original mission of INCLEN to popularize CE, the INCLEN fellows in the country continued to involve in public health activities at the national as well as state level situations. The three branches of analytic domains, namely $\mathrm{CE}$, clinical economics, and health social sciences, continued to flourish, supporting all these research activities in the country. Attempts to apply epidemiologic approach to bedside medicine have gained an accelerated momentum when EBM movement was started and in India also, CE became the major support science for EBM practice. This new facelift in popularization of CE by equipping medical schools with departments of CE and EBM has many challenges which are applicable in the Indian context also. ${ }^{10,11}$ The most important challenge observed is lack of sufficient funding as it is in any other case. Frequent transfer of the trained epidemiologists to distant institutions where CEUs were not in existence, lack of administrative delegations to epidemiologic work, overburdening the trained epidemiologists with other routines like conduct of examinations and running OPDs or call duties in clinical settings, not replacing the key 
positions with appropriately trained clinical epidemiologists, and the prevailing departmentalism and egoistic attitude of the faculty are few other challenges noticed.

In India, epidemiology is very much a part of curriculum in undergraduate courses and presently the department of community medicine is primarily the agency to teach epidemiology. The very purpose of establishment of clinical epidemiology units (CEUs) in medical colleges initiated by INCLEN was to sensitize the clinical faculty towards these broader branches of health sciences which are new and conceptually cross-cutting across different specialities of medicine. ${ }^{12}$ This was also intended to introduce the concepts of outcome-based research, critical appraisal, cost effectiveness, and other qualitative and quantitative research methodologies to the prevailing research culture. Presently, we have nearly twenty such CEUs working in India under the leadership of India-CLEN, which is a country level partner of the INCLEN. The qualified clinical epidemiologists and those fellows trained in clinical health economics and social sciences continue to serve as resource persons in their vicinity. India-CLEN, which was started in 1990 with initial six CEUs, continues to propagate CE and EBM in the country through undertaking good quality research projects as well as promoting teaching-learning activities like regularly conducted journal clubs and seminars in the partner institutions.

\subsection{How far is the idea of CE sold in the Indian context?}

There is no doubt that CE has now become a prudent and well distinctive medical specialty as any other academic discipline. The recent editions of text books and journals and the separate establishments of departments and courses including $\mathrm{PhD}$ programs speak as evidence for this. ${ }^{13-15}$ In the Indian context, the origin of CEUs and academic deliberations in the medical schools with the involvement of INCLEN-trained faculty is yet another evidence for this. Only very little of the work of this facility so far appeared in the national limelight as policy implications. The India-SAFE project (Survey of Abuse in Family Environment in India), which paved way to the Domestic Violence act in India and the IBIS project (Invasive Bacterial Infection Study), which led to the revolutionary changes in pneumonia management, are only few examples. What is more important is the new thrust on quality of medical research, which is visible in many of the medical schools which own these CEUs. Engendering the culture of sound methodological research through epidemiological approach has been taken as a mission by these faculties. Of course, being the members of institutional ethical committees of the respective medical schools where they work, they could also direct many of the research projects towards more prudent human subject protection. By their activities, they could also facilitate more intramural as well as extramural funding for research. As research is something that cannot show immediate visible results, the long lasting output of all this will take its own time.

\subsection{The uncertainty continues}

Clinical decision making is the cognitive element of scientific medical practice. For diagnostic decision making or choice of therapy at the bedside setting, the mind-set of the physician should change towards rationality and maximization of the patient benefit in a social perspective. This is a matter of professionalism and personal attributes of the practicing physician matter more than mere scientific knowledge. The availability of best research evidence is from journals or textbooks and to a certain extent, from standard practice guidelines. For assimilation of this particular knowledge-base which is basically research-publication derived than textbook oriented, critical appraisal skills are needed. Critical appraisal skills are simply based on the core principles of epidemiology. Those who have not understood epidemiology may find it difficult to involve in the process of understanding research publication as well as doing clinical research. Clinical research is important for generating evidence for changing clinical practice towards better patient outcomes. Epidemiology helps to decrease the element of uncertainty in diagnostic and therapeutic decision making process. The readers are requested to look into a previous article which discusses the importance of CE and also the evolution of CE services in India which is helpful to understand the present article. ${ }^{16}$

\section{Linkages between CE and EBM}

There are many questions in this regard that any novice can ask. Is EBM same as CE? Is EBM a parallel concept and threat to CE? Though these are overlapping concepts, EBM and CE are not exactly identical disciplines and the linkages are more evident in the practical applications. In fact, both are complimentary. ${ }^{17} \mathrm{CE}$ and EBM are distinct, not in terms of semantics only, but are separate domains with distinctive theoretical underpinnings, practical applications, and different set of stakeholders for ownership. (An identical phenomenon of jargons is operational research, translational research and implementation research.) EBM is the point of care application of epidemiology and epidemiological approach is needed for posing the right question, evidence generation, evidence appraisal and using the evidence for appropriate decision making as well as incorporating feedback about the practice of EBM. CE is a more inclusive concept and EBM can be considered as an important area of application of principles of $\mathrm{CE}$. Other overlapping academic disciplines like clinical governance and clinical excellence also have scope in the Indian context, especially with the new thrust on CE services and established CEUs. These are concepts developed towards more rational use of resources as well as well-defined standards of care which are applicable to resource-limited settings also. Clinical excellence concentrates on identical methodologies and epidemiology helps for defining quality, outcomes, benchmarks, and other standards for accreditation as well as auditing.

\section{Thoughts for the future}

What is the contribution of epidemiology for effective and efficient functioning of health systems in the Indian context? How we can increase it? Answers to this should come through further academic discussions. Perhaps the inception of CEUs in 
the country is only a good start by the great visionaries under the label of INCLEN. This mission is now facing newer challenges. Private-public divide is to be studied more seriously and clinical 'epidemiology-propagation' should be extended to the private medical establishments also. Involvement of clinical epidemiologists in activities related to public health programs need to be appreciated and more opportunities to be created. This should be seen as a means to bring down the gap between public health and CE (the original schism described by White). Clinical practice is now facing other challenges like practice of defensive medicine, gate keeping by managed care, and increasing commercialization. The 'medical knowledge explosion' of present century warranting continued updating efforts by the practising physicians is another added strain. In this changed setting of clinical practice, it is only natural that there will be emphasis on a newly defined quality and accountabilityelements for clinical practice. The high standards of quality and accountability elements along with optimization of resource use can be achieved only by application of principles of CE. The quality element of health care industry should have a strong foundation of professionalism and all clinical ombudsman activities like clinical audit should be evidencebased. Here is the precise role of epidemiology that all evidence for rational practice should come from properly conducted epidemiological research, appraised by appropriate epidemiological methods and knowledge translational process should be evaluated by scientific methods. Whether we call it EBM or CE is not the issue and what is more important is applying the principles rather than continuing with a complacent attitude. The theoretical teaching learning side can be as CE and practical application can be as EBM. CE services also should be considered as a part of all public health activities along with clinical epidemiological approach being used as a basic analytical tool by all clinicians at the bedside. ${ }^{18}$ Each practitioner should be asking the relevant clinical question about the patient and all practice to be transformed into EBM activity. As there is considerable resource limitation in developed country settings, the efficiency and equity considerations are more important concerns in the Indian context. There should be reorganization of the medical curriculum including more topics on $\mathrm{CE}$, clinical economics (can be considered as a branch of health economics), qualitative research, and bioethics. Capacity generating activities in the medical schools towards accomplishing all these thoughts to reality are the foremost priority in the Indian context.

\section{Proposed structure of CEU}

As initiated by IndiaCLEN (Indian Clinical Epidemiology Network), the CEU will consist of six clinicians, one social scientist, one biostatistician, and one health economist. The importance of health economics in clinical medicine is now well known. ${ }^{19,20}$ These nine medical teachers will be selected from among the middle level faculty members. A senior level faculty member is trained to become the Director of the center. The Principal of the institution acts as Sponsor and the head of the Unit.

\section{Objectives of CEUs}

1. To train sufficient number of middle level faculty members in the medical colleges of the state, and to make them skilled enough to impart CE training to graduate and postgraduate students of these institutions.

2. To conduct affiliated courses in CE like MPhil which is identical to the courses in CE centers in Macmaster, UPEN (University of Pennsylvania), etc. The curriculum includes CE, biostatistics, health economics, health social sciences information technology, and management. The awardees of this course can function as consultants for research projects as well as teachers in epidemiology and occupy the posts of epidemiologists and assist the Government in policy matters related to health problems and priorities.

3. To achieve capacity building through necessary modification of human resource infrastructure and influencing for modification of curriculum for graduate and postgraduate course in Medicine.

4. To undertake good quality research projects for primary data generation in selected areas for addressing the gaps in data for public health planning.

5. To undertake collaborative clinical trials. The network capacity and expertise help in this. At present, the pharmaceutical industry is supporting clinical research and units like research clinical center in some western hospitals can be adapted as role models for functioning of CEUs.

\section{Conclusions}

For scientific practice of medicine in developing countries, research methodology needs to be widely promoted, epidemiology needs to be more popularized and more funds need to be channelized. Local research capacity building is fundamental to this and generation of evidence also needs to be more context-specific than imported from other areas.

Public health orientation of clinical epidemiologists is important because as CE is application of principles of epidemiology in bedside, the domain of CE may continue as the story of the so-called 'abnormals'. Physicians should have a say in the maintenance of health, because they are the primary advocates and advisers to people in all matters of health. The linkage to public health activities is only a means for that. The new group of clinicians with more public health orientation will certainly take lead in the development of CE. The CEU model is perhaps the easily replicable one for propagation of CE and EBM and facilitating public health orientation of clinicians, especially for the developing countries. The establishment of a CEU in all medical schools is a basic step and humble beginning towards this long cherished and noble mission. Broad objectives of such a CEU are listed in the article. Details of administrative attachments, fund provision, and terms of reference for functioning can be developed at the institutional level as Standard operating procedures. Starting the CE unit or EBM unit or epidemiology training center and making it functional is the only way that 
we can do justice to the committed efforts of all great visionaries and their ingenious expertise which was successful to initiate a zeal of enthusiasm for propagation of $C E$ in this country which need to be continued by all means and at any cost.

\section{Conflicts of interest}

The author has none to declare.

\section{R E F E R E N C E S}

1. Sharma RS. Training in epidemiology in India: current status and needs. J Indian Med Assoc. 1984;32:1-3.

2. Dhillon PK, Jeemon P, Arora NK, et al. Status of epidemiology in the WHO South-East Asia region: burden of disease, determinants of health and epidemiological research, workforce and training capacity. Int J Epidemiol. 2012;41:847-860.

3. White KL. Healing the schism. In: Epidemiology, Medicine and the Public's Health. New York: Springer-Verlag; 1991: 107-117.

4. Busse JW, Mills E, Dennis R, et al. Clinical Epidemiology in Oxford Text Book of Public Health. Oxford University Press; $2011: 580-593$.

5. Whelton PK, Gordis L. Epidemiology of clinical medicine. Epidemiol Rev. 2000;22-142.

6. Kishore J. National Health Programs of India. 10th ed. New Delhi, India: Century Publications; 2012:4-6.

7. Jan S, Muraleedharan VK, Andrews S, Bhuveneswari R. Private Sector in the Revised National TB Control Program. A Study of the Implementation of Private Public Partnership Strategy in Tamil Nadu and Kerala: HEFP Working Paper 03/05. 2010. www. esocialsciences.org $>\mathrm{repc}$ [ [accessed on 30.03.16].
8. Tugwell P, Fletcher R, Fletcher S, et al. International clinical epidemiology network. J Gen Intern Med. 2006;21:792-795.

9. Knottnerus JA, Tugwell P. Improving the clinical significance of medical research. J Clin Epidemiol. 2014;67:607-608.

10. Khanjani N, Tabrizi R, Maghsoudi A. The obstacles of teaching evidence based medicine in Iran, from the view point of clinical academics and medical students; a qualitative study. Am J Educ Res. 2013;4:143-148.

11. Mykhalovskiya E, Weirb L. The problem of evidence-based medicine: directions for social science. Soc Sci Med. 2004;59:1059-1069.

12. Lee TH, Goldman L. Models of postdoctoral clinical research training. J Investig Med. 1995;43:250-260.

13. Weiss NS. Clinical epidemiology. In: Rothman KJ, Greenland S, Lash TL, eds. In: Modern Epidemiology 3rd ed. Wolters Kluwer, LippinCott Williams and Wilkins; 2009:641-651.

14. Sackett DL. Clinical epidemiology. Am J Epidemiol. 1969;89:125-127.

15. Fletcher R, Fletcher SW, Fletcher GS. Clinical Epidemiology: The Essentials. Wolterrs Kluwer, Lippincott Williams and Wilkins; 2014:4-6.

16. Pillai RK. Clinical epidemiology: let us join hand s to make it more popular. Clin Epidemiol Global Health. 2015;1-2.

17. Su TT, Bulgiba AM, Sampatanukul P, et al. Clinical epidemiology (CE) and evidence-based medicine (EBM) in the Asia Pacific region (round table forum). Prev Med. 2013;57 (suppl):5-7.

18. Díaz-Vélez C, Soto-Cáceres V, Peña-Sánchez RE, Apolaya Segura MA, Galán-Rodas E. Clinical epidemiology and its relevance for public health in developing countries. Curr Top Public Health. 2013;12:242-246.

19. Eisenberg JM, Freund D, Glick H, Hall J, Halstead S, Labelle R. Clinical economics education in the International Clinical Epidemiology Network. INCLEN economic faculty. J Clin Epidemiol. 1989;42:689-695.

20. Pillai RK. Health economics: theoretical foundations and experience in Indian context. Clin Epidemiol Global Health. 2013;2:96-100. 